\title{
Exploratory Analysis of Biodiesel by Combining Comprehensive Two-Dimensional Gas Chromatography and Multiway Principal Component Analysis
}

\author{
Noroska G. S. Mogollón, ${ }^{*, a, b}$ Fabiana A. L. Ribeiro, ${ }^{a}$ Ronei J. Poppi, ${ }^{a, c}$ \\ Araceli L. Quintana, ${ }^{b}$ Juan A. G. Chávez, ${ }^{b}$ Darwin A. P. Agualongo, ${ }^{b}$ \\ Helga G. Aleme ${ }^{d}$ and Fabio Augusto ${ }^{a, c}$
}

anstituto de Química, Universidade Estadual de Campinas, CP 6154, 13083-970 Campinas-SP, Brazil

${ }^{b}$ Departamento de Investigación, Universidad Estatal de Bolivar, Campus Universitario

Laguacoto II, km 1, vía San Simón, Cantón Guaranda, Provincia Bolívar, Ecuador

'Instituto Nacional de Ciência e Tecnologia (INCT) em Bioanalítica, Departamento de Química Analítica, Instituto de Química, Universidade Estadual de Campinas, 13083-970 Campinas-SP, Brazil

${ }^{d}$ Departamento de Ciências Exatas e da Terra, Instituto de Ciências Ambientais, Químicas e Farmacêuticas, Universidade Federal de São Paulo, Campus Diadema, 09972-270 Diadema-SP, Brazil

\begin{abstract}
Comprehensive two-dimensional gas chromatography $(\mathrm{GC} \times \mathrm{GC})$ was used in this work in order to reveal and identify minor compounds of several raw materials in biodiesel samples, which are not detected by conventional GC analysis. Multiway principal component analysis (MPCA) of the chromatographic profile allowed to identify compounds as C15:1n-3, C18:2n-6, C20:1n-6, C20:3n-3, C20:3n-6, C20:4n-6 C20:5n-3, C21:1n-6, C22:1n-9, C23:1n-9, C24:1n-9 multiunsaturated which were useful tracers to discriminate between biodiesel samples. In this way, the separation power of $\mathrm{GC} \times \mathrm{GC}$ combined with the MPCA algorithm proved to be a valuable strategy for biodiesel samples classification, allowing identification and providing additional compounds of the commonly known as chemical profile of biodiesel samples.
\end{abstract}

Keywords: biodiesel, comprehensive two-dimensional gas chromatography, multiway pattern recognition, multiway principal component analysis

\section{Introduction}

Biodiesel fuel has been used lately as an attractive alternative to the conventional petrodiesel fuel,,$^{1,2}$ mainly due to its renewable nature. Biodiesel is essentially defined as a mixture of monoacyl esters obtained by the solvolysis of vegetal or animal lipids, which can be found in many vegetable species, namely, soy, castor beans, sunflower and dendê or palm oil, as well as in animal fat and fish oil. Hence, these fuels may present high variability in their chemical composition, due to the different raw materials used in their manufacture. ${ }^{3}$ The estimated percentage of the total production of biodiesel derived from soybean oil amounts to $85 \%$, which compromises much of the national production of this vegetable, causing a negative economic impact on the food industry. ${ }^{4}$ Therefore, the search for alternative raw materials as animal fat and recovered soybean oil are becoming interesting options for the production of biodiesel.

*e-mail: Gaby867@gmail.com
Additionally, an economy based on biodiesel fuels induces the development of a sustainable and renewable source of energy, reducing the necessity of importing diesel from abroad and having a positive impact on the country's economy as well as on its environment and society. ${ }^{4}$

The quality of biodiesel is usually evaluated by measuring physicochemical parameters as stability against oxidation, acidity index, ester content, total glycerol and methanol (or ethanol) content, whose standard values can be found reported elsewhere. ${ }^{3,5,6}$ These physicochemical parameters result from the composition of biodiesel, or fatty acid methyl esters (FAME) that reflect the quality of the fuel. Therefore the accurate determination of FAME profile is required to obtain the complete chemical characterization of the oil, in order to better understand its performance parameters. The FAME determination is performed according to the standard regulatory EN $14103,{ }^{7}$ by using gas chromatography coupled with flame ionization detection (GC-FID). Their quantification is performed by the addition of an internal standard in order to minimize 
the possible errors due to sample handling. In this case, a known amount of nonadecanoic acid methyl ester is added. Then, the peaks corresponding from hexanoic acid (C6:0) to nervonic acid methyl ester (C24:1) are integrated and related with the internal standard to finally express the content of fatty acid as mass percentage.

However, coelution can be found in the biodiesel samples, as a result of the structural similarity of some fatty acids, which are hardly resolved by GC-FID, ${ }^{3}$ another drawback is the detection of the minority compounds that, due to their low concentration, normally exhibit low detectability with technique, hence, an increase in the separation and detection power is required in order to improve the reliability of the results. ${ }^{1-3}$

In this regard, two-dimensional gas chromatography $(\mathrm{GC} \times \mathrm{GC})$ has been used as an interesting tool which offers an increased peak of capacity (number of peaks that can be separated in a run chromatography) in comparison with conventional GC. ${ }^{8,9}$ In this system the entire sample is subjected to the separation mechanisms of the two coupled stationary phases, which have different selectivity or polarity index, in order to separate compounds that suffer coelution in the first dimension (GC). ${ }^{8-10}$

A remarkable advantage of comprehensive GC is the presence of structured chromatograms, in which the compounds are organized in a structured plane building characteristic recognizable patterns. In this way, compounds with chemical similarity are grouped into "clusters" which facilitate visual inspection and give greater identification reliability. ${ }^{8-11}$

Thus, this technique has revealed many traceconstituents that are present in common samples, leading to a discovery of new markers in different areas, such as, metabolomics, proteomics, petrochemicals and biofuels. ${ }^{12-14}$

It also is worth noting that, as result of the high dimensionality of this technique, a huge amount of information is acquired and the use of multivariate statistical techniques, such as chemometrical tools, is required in order to extract useful chemical information. ${ }^{15,16}$ Concerning this matter, multiway principal component analysis (MPCA) has been often used for exploratory analysis of high order data set obtained in GC $\times$ GC analysis. ${ }^{17,18}$ This method allows to identify similarities among samples from the GC $\times$ GC profile and this information can be later used for sample classification.

The MPCA technique unfold the data cube $\mathbf{X}(\mathrm{I}, \mathrm{J}, \mathrm{K})$ into an $\mathbf{X}(\mathrm{I}, \mathrm{JK})$ matrix which is sequentially decomposed as the product of a score $\left(\mathbf{T}_{\mathbf{k}}\right)$ and loading $\left(\mathbf{P}_{\mathbf{k}}^{\mathbf{T}}\right)$ matrices with $\mathrm{k}$ factors, just as those in ordinary two-way principal components analysis (PCA). Equation 1 describes this decomposition, where the $\mathbf{E}_{\mathbf{k}}=$ residue matrix. ${ }^{14,16}$
$\mathbf{X}=\mathbf{T}_{\mathbf{k}} \times \mathbf{P}_{\mathrm{k}}^{\mathbf{T}}+\mathbf{E}_{\mathrm{k}} \quad \mathrm{k}=$ ideal factor number

One of the main requirements to apply this algorithm is the presence of highly reproducible retention time in both GC dimensions, which is difficult to achieve, for this reason various post-data processing methods have been developed to overcome this problem. ${ }^{19,20}$

MPCA was used with comprehensive two-dimensional gas chromatography with time-of-flight mass spectrometer (GC $\times$ GC-TOF-MS) in order to identify the differences in chemical composition between three different species of plants and two types of extracts, providing a direct relation between the different metabolite concentrations. ${ }^{21}$ Ventura et al. ${ }^{17}$ used MPCA on large numbers of specific chemical components resolved with GC $\times$ GC-FID to determine the molecular relation of eight different maltene fractions of crude oils and performed a classification between the samples.

However, the combined use of MPCA with data from $\mathrm{GC} \times \mathrm{GC}$ for the analysis of bio-fuels as biodiesel is quite incipient. In this sense the current study proposes a new analytical methods to classify biodiesel samples, by using GC $\times$ GC-FID and two dimensional gas chromatography fast quadrupole mass spectrometry (GC $\times$ GC-QMS), in order to detect and identify possibly new compounds, through the increment of the sensitivity, resolution and detectability of the multidimensional technique that can be used for discriminate the biodiesel samples prepared from soybean oil, canola oil, corn oil, unprocessed soybean oil, used soybean oil, bovine fat, and sunflower oil by MPCA.

\section{Experimental}

\section{Materials and methods}

The raw material used for the biodiesel formulation (soybean, corn, canola, sunflower and bovine fat) were locally obtained (Campinas, SP, Brazil). FAME analytical standards (Sigma-Aldrich, Bellefonte, PA, USA) were used to confirm the identity of the FAMEs present in the different biodiesels by comparing the mass spectrum of the individual components present in the sample and the standard commercial FAME, and a series of $n$-alkanes C8-C24 (Sigma-Aldrich) were used to determine the corresponding Van den Dool and Kratz Index for each compound, in order to determine retention indices of the components and ensure an accurate identification of the compounds present in the biodiesel. HPLC-grade methanol and sodium hydroxide (Supelco, Bellefonte, PA, USA) were used for biodiesel production. 


\section{Preparation of biodiesels}

Synthesis of biodiesel was carried out mixing $5.0 \pm 0.5 \mathrm{~mL}$ of the oils mentioned above with a defined amount of methanol (6:1 molar ratio to oil) premixed with $0.5 \% \mathrm{~m} / \mathrm{m}$ of sodium hydroxide, in $40 \mathrm{~mL}$ with septum-sealed glasses vials. These vials were sonicated for $30 \mathrm{~min}$ at $32{ }^{\circ} \mathrm{C}$ in a thermostatic ultrasound water bath. ${ }^{22}$ Subsequently, the inorganic constituents and other products were eliminated from the biodiesel by washing it with $10 \% \mathrm{~m} / \mathrm{v}$ aqueous sodium chloride solution and drying over anhydrous sodium sulfate to ensure residual water remotion. Six separated batches of biodiesel from each different source were prepared and analysed. ${ }^{1,22}$

\section{Chromatographic methods}

\section{GCxGC-FID and GC×GC-QMS}

The GC $\times$ GC-FID prototype was based on the HP-6890 Series II GC-FID (Agilent, Santa Clara, CA, USA) previously described, ${ }^{23,24}$ running in split mode (split ratio 50:1) equipped with a miniaturized sealed two-stage cryogenic modulator, the controller used for the modulator was a low cost 8-bitDuemilanove microcontroller board (Arduino, Ivrea, Italy) ${ }^{25}$ hydrogen at $0.7 \mathrm{~mL} \mathrm{~min}^{-1}$ was used as carrier gas and the column set consisted on a $30 \mathrm{~m} \times 0.25 \mathrm{~mm} \times 0.25 \mu \mathrm{m}$ HP-5 (5\% phenylmethysiloxane) column (Agilent Technologies, Palo Alto, CA, USA) connected to a highly polar $1.0 \mathrm{~m} \times 0.10 \mathrm{~mm} \times 0.08 \mu \mathrm{m}$ SLB-IL61 ionic liquid 1,12-di(tripropylphosphonium) dodecane bis(trifluoromethylsulfonyl) imide trifluoromethylsulfonate (Supelco, Bellefonte, PA, USA). The modulation period was set to $6.0 \mathrm{~s}$ and data acquisition frequency was $100 \mathrm{~Hz}$. The oven temperature was programmed from 170 to $275^{\circ} \mathrm{C}$ at $3{ }^{\circ} \mathrm{C} \mathrm{min}^{-1}$, and the injector and detector temperatures were set at 250 and $275^{\circ} \mathrm{C}$, respectively.

The GC $\times$ GC-QMS system consisted in a modified QP2010+ (Shimadzu, Kyoto, Japan) GC-QMS fitted with a split-splitless injector (split ratio 1:10) with the cryogenic modulator mentioned above. The column set and other chromatographic conditions were the same as described above. The ion source temperature was set to $230^{\circ} \mathrm{C}$. The detector was programmed to turn off the ionization power to avoid damage during the elution of majoritarian compounds (such as $\mathrm{C} 16: 0$ and $\mathrm{C} 18: 0$ methyl esters). The mass scan range was set from $m / z 40$ to 283 , yielding an acquisition rate of 25 spectra per second. The identification of the peaks were performed by comparing the sample spectra against FFNSC (Chromaleont, Messina, Italy) and NIST 2008 (NIST, Gaithersburg-MD, USA) along with the linear temperature program retention indexes (LTPRI)..$^{26,27}$

\section{Results and Discussion}

The GC $\times$ GC-FID and GC $\times$ GC-QMS chromatograms were digitalized using Chemstation (Agilent, Wilmington, EUA) and GCMS Solution (Agilent, Wilmington, EUA) softwares, respectively. GCImage (Zoex, Houston, USA) software was used for identification and to generate the figures. The data set were folded and aligned by using correlation optimized warping (COW), ${ }^{19,20}$ and MPCA was performed using PLS Toolbox 4.0 (Eigenvector Technologies, Manson, EUA) running on MatLab 7.8 environment (MathWorks, Natick-MA, USA) ${ }^{28,29}$ MPCA was carried out using GC $\times$ GC-FID chromatograms of biodiesels obtained from different vegetable and animal oils (Figure 1), in order to identify what type of compounds are statistically different in the biodiesels of several raw materials, focusing our search on minor compounds and in those that are overlaid, which are hardly detected and resolved by conventional methodologies currently used.

The studied compounds that can be identified within the biodiesel from raw materials are listed in Table 1. These include methyl esters as C11:0, C12:0 and C13:0; found mostly in animal biodiesel and rarely reported during the analysis by conventional techniques due to its low concentrations in the biofuel. On the other hand, C17:1, C18:2n-6, C20:1n-6, C20:3n-3, C20:4n-6, C20:5n-3, C21:0, C22:0, C22:1n-9 C23:0 and C24:0 were detected in most of analyzed biodiesel vegetal sources, which are not reported in the regulatory standard norm EN 14103.

These compounds are mostly unsaturated and exhibit coelution by conventional methods of analysis, making the separation by the international standard methods difficult.

MPCA (98.71\% of total variance with 2 factors) analysis allowed to clearly indentify the seven types of oil samples: bovine fat, soybean, unprocessed soybean, recovered soybean, sunflower, corn and canola (Figure 2).

Factor 1 explains $80.3 \%$ of total sample variance and are essentially responsible for discriminating the processed soybean biodiesel from other sources and from biodiesel of recovered soybean oil. Factor 2 describes $18.41 \%$ of total variance and is related to the increasing levels of soybean oil in samples. The compounds associated to the discriminating power of each factor can be identified by the loadings of the MPCA model, no outliers were detected on Figure 2. Each factor was separately plotted for a better visualization of the positive and negative values (Figures 3 ). Loading plots visually resemble $\mathrm{GC} \times \mathrm{GC}$ chromatograms and provide the contribution of each given variable to the factors. Their interpretation allows identifying the chemical profile of clusters samples. 

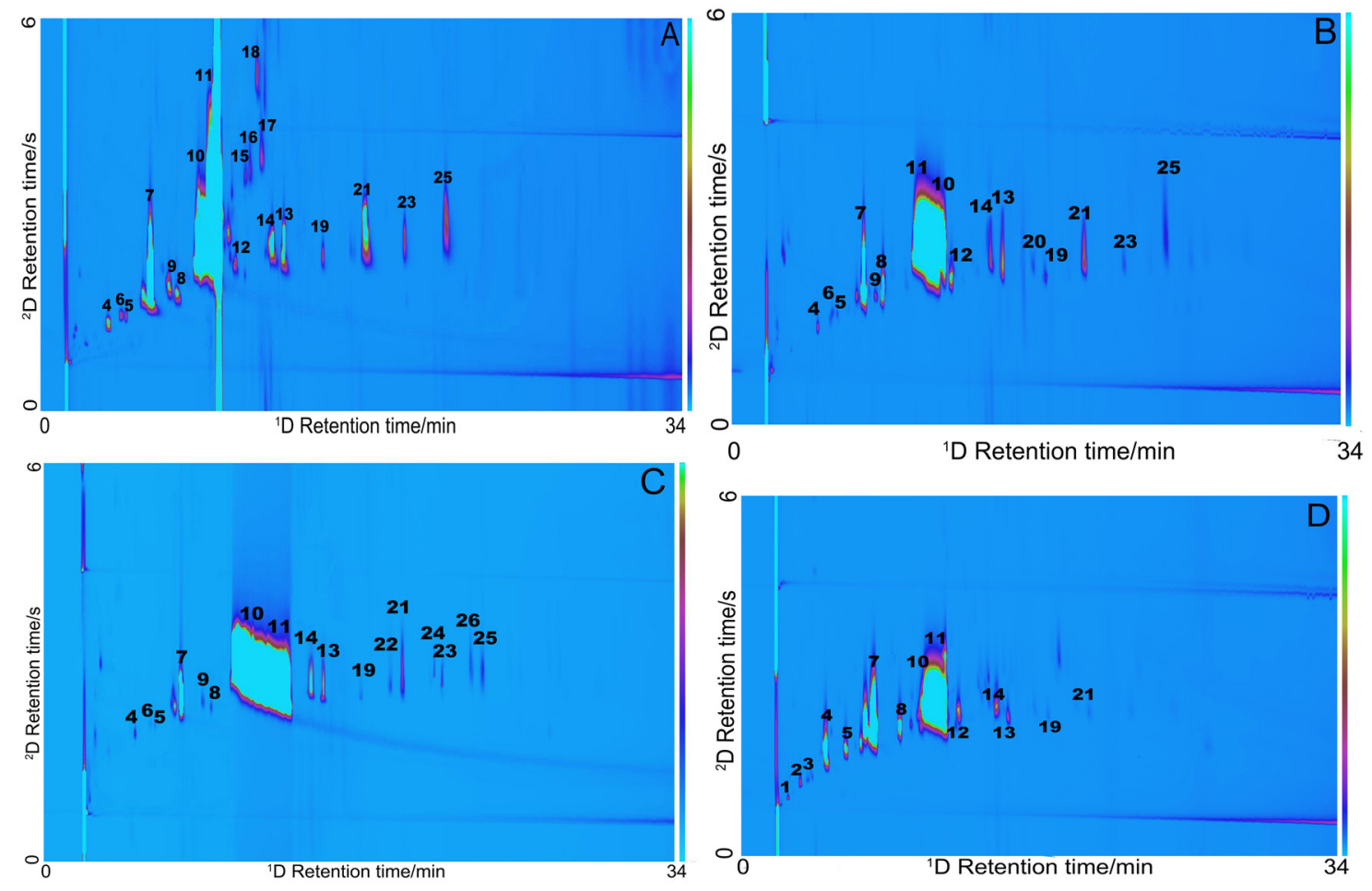

Figure 1. Chromatographic profiles obtained in a GC×GC-FID system, (A) soybean biodiesel; (B) unprocessed soybean biodiesel; (C) canola biodiesel; (D) bovine fat biodiesel.

The positive loading values of factor 1 and 2 are very similar (Figures 3a and 3c) and only a few contributions are discriminating the samples. On the contrary, the plots for negative values of these factors are quite different, and allow the identification of the chromatographic regions that result responsible for discriminating the biodiesel samples types (Figures 3b and 3d).

The chromatographic peak areas corresponding to the positive contributions of loadings on factors 1 and 2 are attributed to the peaks related to the compound classes C14:0, C15:0, C15:1n-3, C17:0, C17:1, C20:0, C20:1n-6, $\mathrm{C} 21: 0, \mathrm{C} 22: 0, \mathrm{C} 23: 0$ and $\mathrm{C} 24: 0$, that are present in all of the studied biodiesel samples. Negative contributions (Figures $3 \mathrm{~b}$ and $3 \mathrm{~d}$ ) of loadings on factors 1 and 2 were assigned to those chromatographic peaks associated to each sample class and can be designated as biodiesel source marker.

For factor 1, these compounds are: C18:2n-6, C20:3n-3, C20:3n-6, C20:4n-6 and C20:5n-3 (not present in canola and bovine fat) and $\mathrm{C} 21: 1 \mathrm{n}-6$ (only detected in unprocessed soybean), and for factor 2: C11:0, C12:0, C13:0 (only found in bovine fat), C22:1n-9, C23:1n-9 (found in corn, sunflower and canola biodiesels) and C24:1n-9 (only in canola biodiesel).

Differences between biodiesel based on animal and vegetal sources were evidenced by these results. Most of the compounds found in biodiesel samples from animal fat are saturated and some of them were detected even at very low concentrations. In contrast, in biodiesels from vegetable sources most of the markers found are polyunsaturated, which leads to a clear distinction between these biodiesel in the graphic scores.

The compounds related to the negative contributions of loadings correspond to the minor constituents and to the polyunsaturated compounds and they were identified only due to the increased detectability inherent to GC $\times \mathrm{GC}$.

MPCA can provide information about the chromatograms regions that are responsible for discriminating the various analyzed biodiesel samples which can be used to build classification models.

In this sense, the association of $\mathrm{GC} \times \mathrm{GC}$ with MPCA demonstrates the importance of these minor constituents and polyunsaturated compounds to the distinction of biodiesel source (vegetable or animal raw material). This suggests that these compounds should be introduced into routine protocols that aim to ensure a better quality of specific biodiesels.

\section{Conclusions}

The proposed method associates the separation power of $\mathrm{GC} \times \mathrm{GC}$ with the multivariate approach of MPCA in order to identify new compounds that successfully discriminate biodiesel samples from different raw materials (soybean, 
Table 1. Components identified on biodiesels from vegetal source and animal fat

\begin{tabular}{|c|c|c|c|c|c|c|c|c|c|c|c|c|}
\hline \multirow{2}{*}{ No. } & \multirow{2}{*}{ FAME } & \multirow{2}{*}{ Formula } & \multicolumn{2}{|c|}{ LTPRI $^{\mathrm{a}}$} & \multirow{2}{*}{$\mathrm{M}^{\mathrm{b}}$} & \multirow{2}{*}{$\mathrm{S}$} & \multirow{2}{*}{ SR } & \multirow{2}{*}{ SNP } & \multirow{2}{*}{$\mathrm{CO}$} & \multirow{2}{*}{ SF } & \multirow{2}{*}{$\mathrm{C}$} & \multirow{2}{*}{$\mathrm{BF}$} \\
\hline & & & Exp. & Lit. & & & & & & & & \\
\hline 1 & Me-undecanoate, C11:0 & $\mathrm{C}_{12} \mathrm{H}_{24} \mathrm{O}_{2}$ & 1455 & 1421 & 839 & & & & & & & $\mathrm{X}$ \\
\hline 2 & Me-dodecanoate, C12:0 & $\mathrm{C}_{13} \mathrm{H}_{26} \mathrm{O}_{2}$ & 1629 & 1633 & 890 & & & & & & & $\mathrm{X}$ \\
\hline 3 & Me-tridecanoate, C13:0 & $\mathrm{C}_{14} \mathrm{H}_{28} \mathrm{O}_{2}$ & 1724 & 1720 & 880 & & & & & & & $\mathrm{X}$ \\
\hline 4 & Me-tetradecanoate, C14:0 & $\mathrm{C}_{15} \mathrm{H}_{30} \mathrm{O}_{2}$ & 1735 & 1723 & 938 & $\mathrm{X}$ & $\mathrm{X}$ & $\mathrm{X}$ & $\mathrm{X}$ & $\mathrm{X}$ & $X$ & $\mathrm{X}$ \\
\hline 5 & Me-pentadecanoate, C15:0 & $\mathrm{C}_{16} \mathrm{H}_{32} \mathrm{O}_{2}$ & 1826 & 1824 & 806 & $\mathrm{X}$ & $\mathrm{X}$ & $\mathrm{X}$ & $\mathrm{X}$ & $\mathrm{X}$ & $\mathrm{X}$ & $\mathrm{X}$ \\
\hline 6 & Me-pentadecenoate, C15:1n-3 & $\mathrm{C}_{16} \mathrm{H}_{28} \mathrm{O}_{2}$ & 1818 & - & - & $X$ & $X$ & $\mathrm{X}$ & $\mathrm{X}$ & $\mathrm{X}$ & $X$ & \\
\hline 7 & Me-hexadecanoate, C16:0 & $\mathrm{C}_{17} \mathrm{H}_{34} \mathrm{O}_{2}$ & 1892 & 1886 & 907 & $\mathrm{X}$ & $\mathrm{X}$ & $\mathrm{X}$ & $\mathrm{X}$ & $\mathrm{X}$ & $\mathrm{X}$ & $\mathrm{X}$ \\
\hline 8 & Me-heptadecanoate, C17:0 & $\mathrm{C}_{18} \mathrm{H}_{36} \mathrm{O}_{2}$ & 2027 & 2030 & 836 & $\mathrm{X}$ & $\mathrm{X}$ & $\mathrm{X}$ & $\mathrm{X}$ & $\mathrm{X}$ & $\mathrm{X}$ & $\mathrm{X}$ \\
\hline 9 & Me-12-heptadecanoate, C17:1 & $\mathrm{C}_{18} \mathrm{H}_{34} \mathrm{O}_{2}$ & 2007 & 2003 & - & $\mathrm{X}$ & $\mathrm{X}$ & $\mathrm{X}$ & $\mathrm{X}$ & $\mathrm{X}$ & $\mathrm{X}$ & \\
\hline 10 & Me-octadecanoate, C18:0 & $\mathrm{C}_{19} \mathrm{H}_{38} \mathrm{O}_{2}$ & 2008 & 2013 & 860 & & & & & & & $\mathrm{X}$ \\
\hline 11 & Me-9,12-octadecenoate, C18:2n-6 & $\mathrm{C}_{19} \mathrm{H}_{34} \mathrm{O}_{2}$ & 2096 & 2092 & - & $\mathrm{X}$ & $\mathrm{X}$ & $\mathrm{X}$ & & & $\mathrm{X}$ & \\
\hline 12 & Me-nonadecanoate, C19:0 & $\mathrm{C}_{20} \mathrm{H}_{40} \mathrm{O}_{2}$ & 2234 & 2235 & 900 & $\mathrm{X}$ & $\mathrm{X}$ & $\mathrm{X}$ & $\mathrm{X}$ & $\mathrm{X}$ & $\mathrm{X}$ & $\mathrm{X}$ \\
\hline 13 & Me-eicosanoate, C20:0 & $\mathrm{C}_{21} \mathrm{H}_{42} \mathrm{O}_{2}$ & 2332 & 2332 & 837 & $\mathrm{X}$ & $\mathrm{X}$ & $\mathrm{X}$ & $\mathrm{X}$ & $\mathrm{X}$ & $\mathrm{X}$ & $\mathrm{X}$ \\
\hline 14 & Me-14-eicosenoate, C20:1n-6 & $\mathrm{C}_{21} \mathrm{H}_{40} \mathrm{O}_{2}$ & 2308 & 2310 & - & $\mathrm{X}$ & $\mathrm{X}$ & $\mathrm{X}$ & $\mathrm{X}$ & $\mathrm{X}$ & $\mathrm{X}$ & $\mathrm{X}$ \\
\hline 15 & Me-eicosapentaenoate, C20:3n-3 & $\mathrm{C}_{21} \mathrm{H}_{38} \mathrm{O}_{2}$ & 2286 & - & - & $\mathrm{X}$ & $\mathrm{X}$ & $\mathrm{X}$ & $\mathrm{X}$ & $\mathrm{X}$ & & \\
\hline 16 & Me-8,11,14-eicosatrienoate, C20:3n-6 & $\mathrm{C}_{21} \mathrm{H}_{38} \mathrm{O}_{2}$ & 2246 & 2274 & - & $\mathrm{X}$ & $\mathrm{X}$ & $\mathrm{X}$ & $\mathrm{X}$ & $\mathrm{X}$ & & \\
\hline 17 & Me-5,8,11,14-eicosatetraenoate, C20:4n-6 & $\mathrm{C}_{21} \mathrm{H}_{32} \mathrm{O}_{2}$ & 2258 & 2282 & - & $\mathrm{X}$ & $\mathrm{X}$ & $\mathrm{X}$ & $\mathrm{X}$ & $\mathrm{X}$ & & \\
\hline 18 & Me-5,8,11,14,17-eicosapentanoate, C20:5n-3 & $\mathrm{C}_{21} \mathrm{H}_{32} \mathrm{O}_{2}$ & 2301 & 2300 & 805 & $\mathrm{X}$ & $\mathrm{X}$ & $\mathrm{X}$ & $\mathrm{X}$ & $\mathrm{X}$ & & \\
\hline 19 & Me-heneicosanoate, C21:0 & $\mathrm{C}_{22} \mathrm{H}_{44} \mathrm{O}_{2}$ & 2428 & 2428 & - & $\mathrm{X}$ & $\mathrm{X}$ & $\mathrm{X}$ & $\mathrm{X}$ & $\mathrm{X}$ & $\mathrm{X}$ & $\mathrm{X}$ \\
\hline 20 & Me-heneicosenoate, C21:1n-6 & $\mathrm{C}_{22} \mathrm{H}_{42} \mathrm{O}_{2}$ & 2310 & - & - & & & $\mathrm{X}$ & & & & \\
\hline 21 & Me-docosanoate, C22:0 & $\mathrm{C}_{23} \mathrm{H}_{46} \mathrm{O}_{2}$ & 2505 & 2530 & 920 & $\mathrm{X}$ & $\mathrm{X}$ & $\mathrm{X}$ & $\mathrm{X}$ & $\mathrm{X}$ & $\mathrm{X}$ & $\mathrm{X}$ \\
\hline 22 & Me-13-docosenoate, C22:1n-9 & $\mathrm{C}_{23} \mathrm{H}_{44} \mathrm{O}_{2}$ & 2500 & 2507 & 881 & & & & $\mathrm{X}$ & $\mathrm{X}$ & $\mathrm{X}$ & \\
\hline 23 & Me-tricosanoate, C23:0 & $\mathrm{C}_{24} \mathrm{H}_{48} \mathrm{O}_{2}$ & 2634 & 2628 & 900 & $\mathrm{X}$ & $\mathrm{X}$ & $\mathrm{X}$ & $\mathrm{X}$ & $\mathrm{X}$ & $\mathrm{X}$ & \\
\hline 24 & Me-tricosenoate, C23:1n-9 & $\mathrm{C}_{24} \mathrm{H}_{46} \mathrm{O}_{2}$ & 2460 & 2458 & 800 & & & & $\mathrm{X}$ & $\mathrm{X}$ & $\mathrm{X}$ & \\
\hline 25 & Me-tetracosanoate, C24:0 & $\mathrm{C}_{25} \mathrm{H}_{50} \mathrm{O}_{2}$ & 2730 & 2731 & 854 & $X$ & $\mathrm{X}$ & $\mathrm{X}$ & $\mathrm{X}$ & $\mathrm{X}$ & $\mathrm{X}$ & \\
\hline 26 & Me-tetracosenoate, C24:1n-9 & $\mathrm{C}_{25} \mathrm{H}_{48} \mathrm{O}_{2}$ & 2694 & 2700 & 804 & & & & & & $\mathrm{X}$ & \\
\hline
\end{tabular}

${ }^{a}$ LTPRI: linear temperature program retention indexes, measured (Exp.) and found in the MS databases (Lit.); ${ }^{\mathrm{b}}$ spectral match with reference spectra on NIST 2008 library and FFNSC; FAME: fatty acid methyl esters; S: soybean oil; SR: recovered soybean oil; SNP: unprocessed soybean oil; CO: corn oil; SF: sunflower oil; C: canola oil; BF: bovine fat.

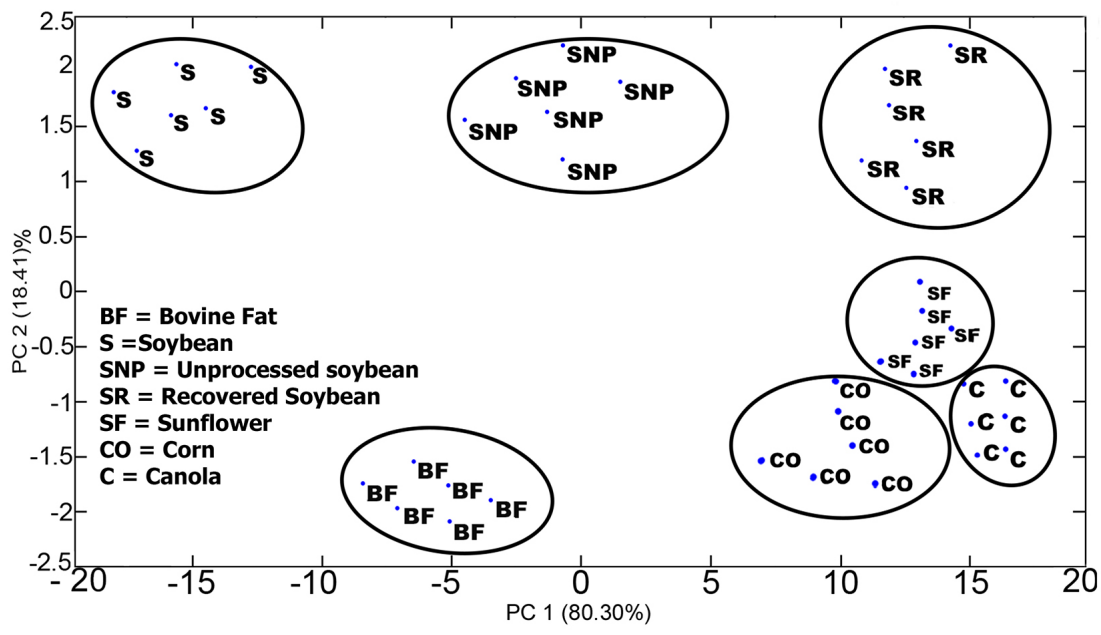

Figure 2. Factors 1 and 2 form score plots from MPCA of $\mathrm{GC} \times \mathrm{GC}$ profiles of biodiesel samples. 

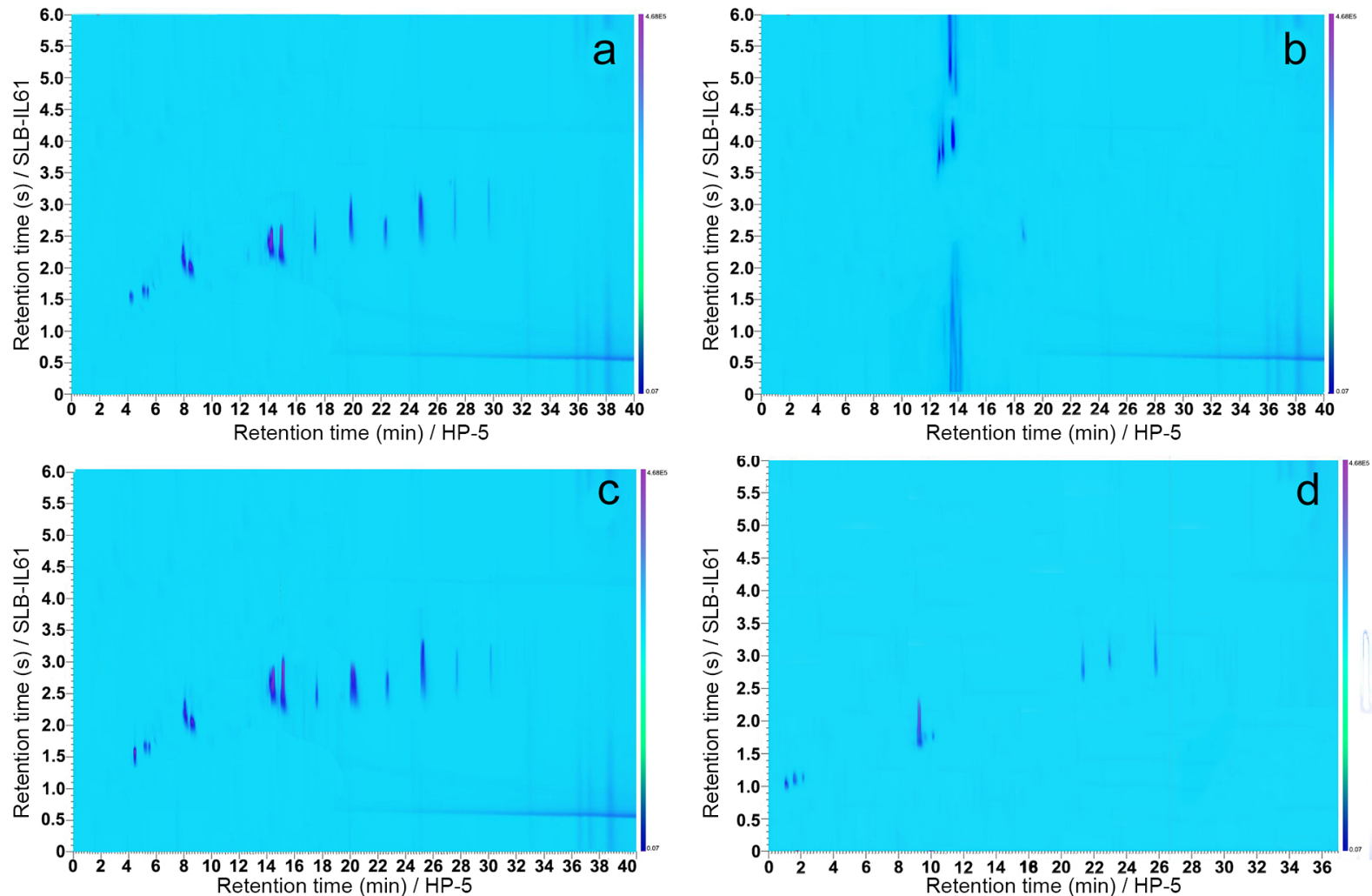

Figure 3. Representation of the loadings responsible for the differentiation of biodiesel, (a) positive contributions for factor 1; (b) negative contributions for factor 1; (c) positive contributions for factor 2; (d) negative contribution for factor 2.

recovered soybean, unprocessed soybean canola, sunflower, bovine fat and corn) and to constitute a powerful alternative to improve routine protocols to test the biodiesel's quality. The method also allows to identify characteristic compounds of each class, that can be used as chemical markers of biodiesel sources, as well as major compounds present in all samples.

Compounds such as C14:0, C15:0, C15:1n-3, C17:0, C17:1, C20:0, C20:1n-6, C21:0, C22:0, C23:0 and $\mathrm{C} 24: 0$ are present in soybean, sunflower, corn and canola biodiesel, mostly associated with biodiesel from vegetable sources, Most of these compounds are polyunsaturated and have relatively low concentrations, which makes them only detectable due to the inherent characteristic of improvement in detectability, resolution and sensitivity offered by comprehensive GC. While saturated compounds such as C11:0, C12:0, C13:0, $\mathrm{C} 14: 0, \mathrm{C} 15: 0$ were predominant in biodiesel from animal sources.

\section{Acknowledgments}

The Brazilian Ministry of Education Agency for Improvement of Graduate Personnel (CAPES), the National Council for Scientific and Technological Development
(CNPq) and the São Paulo Research Foundation (FAPESP) are gratefully acknowledged for providing funding for this research.

\section{References}

1. Chhetri, A. B.; Islam, M. R.; Energy Sources, Part A 2008, 30, 754.

2. European Parliament and Council; Directive 98/70/EC of the European Parliament and of the Council, Relating to the Quality of Petrol and Diesel Fuels as Amended by Directive 2009/30/ EC, 13 October 1998.

3. Fangrui, M.; Hanna, M.; Bioresour. Technol. 1999, 70, 1.

4. Paulillo, L. F.; Vian, C. E. F.; Shikida, P. F. A.; Mello, F. T.; Rev. Econ. Sociol. Rural 2007, 45, 531.

5. EN 14331: Liquid Petroleum Products Separation and Characterization of Fatty Acid Methyl Esters (FAME) from Middle Distillate Fuels, European Committee for Standardization: Brussels, 2004.

6. Mittelbach, M.; Bioresour. Technol. 1996, 56, 7.

7. EN 14103: Fat and Oil Derivatives, Fatty Acid Methyl Esters (FAME) Determination of Ester and Linolenic Acid Methyl Ester Content, European Committee for Standardization: Brussels, 2011.

8. Giddings, J. C.; Anal. Chem. 1984, 56, 1258A. 
9. Ventramani, C. J.; Xu, J. Z.; Phillips, J. B.; Anal. Chem. 1996, $68,1486$.

10. Eiserbeck, C.; Nelson, R. K.; Grice, K.; Curiale, J.; Reddy, C. M.; Raiteri, P.; J. Chromatogr. A 2011, 1218, 5549.

11. Jalali-Heravi, M.; Parastar, H.; Talanta 2011, 85, 835.

12. Beckstrom, A. C.; Humston, E. M.; Snyder, L. R.; Synovec, R. E.; Juul, S. E.; J. Chromatogr. A 2011, 1218, 1899.

13. Hantao, L. W.; Toledo, B. R.; Ribeiro, F. A. L.; Pizetta, M.; Pierozzi, C. G.; Furtado, E. L.; Augusto, F.; Talanta 2013, 116, 1079.

14. Aguiar, A.; Silva Jr., A. I.; Azevedo, D. A.; Aquino Neto, F. R.; Fuel 2010, 89, 2760.

15. Brereton, R. G.; Chemometrics: Data Analysis for the Laboratory and Chemical Plant; John Wiley \& Sons Inc, Wiley: Chichester, UK, 2003.

16. Wold, S.; Geladi, P.; Esbensen, K.; J. Chemom. 1987, 1, 41.

17. Ventura, G. T.; Hall, G. J.; Nelson, R. K.; Frysinger, G. S.; Raghuraman, B.; Pomerantz, A. E.; Mullins, O. C.; Reddy, C. M.; J. Chromatogr. A 2011, 1218, 2584.

18. Mispelaar, V. G. V.; Tas, A. C.; Smilde, A. K.; Schoenmakers, P. J.; Asten, A. C. V.; J. Chromatogr. A 2003, 1, 15.

19. Nielsen, N. P. V.; Carstensen, J. M.; Smedsgaard, J.; J. Chromatogr. A 1998, 805, 17.
20. Christensen, J. H.; Tomasi, G.; Hansen, A. B.; Environ. Sci. Technol. 2005, 39, 255.

21. Pierce, K. M.; Hope, J. L.; Hoggard, J. C.; Synovec, R. E.; Talanta 2006, 70, 797.

22. Omotola, B.; Patrick, L.; Bamikole, A.; Energies 2010, 3, 1691.

23. Pedroso, M. P.; Ferreira, E. C.; Hantao, L. W.; Bogusz Jr., S.; Augusto, F.; J. Sep. Sci. 2011, 34, 1534.

24. de Godoy, L. A. F.; Hantao, L. W.; Pedroso, M. P.; Poppi, R. J.; Augusto, F.; Anal. Chim. Acta 2011, 699, 120.

25. Bogusz Jr., S.; Hantao, L. W.; Braga, S. C. G. N.; França, V. C. R. M.; da Costa, M. F.; Hammer, R. D.; Ventura, D. F.; Augusto, F.; J. Sep. Sci. 2012, 35, 2438.

26. NIST/EPA/NIH Mass Spectral Database (NIST 08) and NIST Mass Spectral Search Program, Version 2.0g; The National Institute of Standards and Technology (NIST), USA.

27. van den Dool, H.; Kratz, P. D.; J. Chromatogr. A 1963, 11, 463.

28. PLS Toolbox 4.0; Eigenvector Research Inc., USA, 2006.

29. MatLab, Version 7.13; The MathWorks Inc., USA, 2011 b.

Submitted: May 2, 2016

Published online: August 2, 2016

FAPESP has sponsored the publication of this article. 